\title{
Symptomatic tonsillar ectopia
}

\author{
Kazuhide Furuya, Keiji Sano, Hiromu Segawa, Katsuhisa Ide, Hidehiko Yoneyama
}

\begin{abstract}
Objective-To determine if slight descent of the cerebellar tonsils $(<5 \mathrm{~mm}$ below the foramen magnum; tonsillar ectopia) may cause surgically treatable symptomatology.

Methods-A consecutive series of nine symptomatic patients with tonsillar ectopia seen between December 1990 and March 1993 are reported on. The same number of age and sex matched controls were selected at random from outpatients. Twelve asymptomatic subjects with tonsillar ectopia were found among 5000 people between January 1991 and March 1996. Diagnosis of tonsillar ectopia was based on midsagittal MRI.
\end{abstract}

Results-Patients presented mainly with chronic intractable occipital dull pain, vertigo, and dysequilibrium. In all patients MRI showed normal brain structure except for tonsillar ectopia (-2.9 (SD 0.8) $\mathrm{mm}$ ), which has historically been thought to be of no clinical relevance. In the control group the tonsilar position was +2.1 (SD 2.8) $\mathrm{mm}(\mathrm{p}<0.01)$. Neurotologically abnormal findings were detected with a monaural speech integration test $(100 \%)$, eye tracking test $(56 \%)$, optokinetic nystagmus test $(89 \%)$, and visual suppression test $(67 \%)$ which strongly suggested a CNS lesion. In accordance with the results of MRI and precise neurotological examination, posterior fossa decompression surgery was carried out, followed by improvement of preoperative symptoms and less severity of neurotological abnormalities in all patients. Conclusion-Tonsillar ectopia could cause neurological symptoms in small populations, which were surgically treatable. Neurotological assessment was necessary to verify the aetiological relation between tonsillar ectopia and various symptoms.

(F Neurol Neurosurg Psychiatry 1998;64:221-226)

Keywords: Chiari type I malformation; magnetic resonance image; neurotological examination; tonsillar ectopia

Correspondence to: Dr Kazuhide Furuya, National Institute of Neurological Disorders and Stroke, Stroke Branch Building 36, Room 4A03, Bethesda, Maryland 20892-4128, USA. Telephone 0011301496 6579; Fax 0011301402 2769 .

Received 22 November 1996 and in revised form 15 May 1997

Accepted 5 June 1997

Chiari Type I malformation is a well known disease involving caudal descent of the cerebellar tonsils and is occasionally associated with syringomyelia. ${ }^{1-9}$ In 1891 and 1895 , Chiari ${ }^{12}$ precisely described this malformation and related ones, which he designated type II, type $\mathrm{III}^{1}$, and type $\mathrm{IV}^{2}$ malformation. He speculated that this condition, which is a herniation of the posterior fossa contents below the level of the foramen magnum, is caused by hydrocephalus. ${ }^{12}$ Recently, many authors have used the term "Chiari type I malformation" to describe tonsillar herniation with and without hydrocephalus, resulting in confusion regarding the meaning of this term. ${ }^{347910}$ We identified through neurotological examinations several cases of descent of the cerebellar tonsils to less than $5 \mathrm{~mm}$ below the foramen magnum (tonsillar ectopia) in which the patients experienced medically intractable dull pain in the occipital area and cerebellovestibular dysfunction symptoms. These patients underwent posterior fossa decompression surgery, following which their clinical symptoms improved. In this report, we propose implications of chronic intractable occipital dull pain and cerebellovestibular dysfunction in patients with tonsillar ectopia.

Subjects and methods GENERAL POPULATION STUDY

We analysed 5000 subjects to check the degree of descent of the cerebellar tonsils below the level of the foramen magnum between January 1991 and March 1996. They were people who wished to check their neurological status. We found 12 subjects with asymptomatic tonsillar ectopia among them $(0.24 \%)$. There were four men and eight women ranging in age from 24 to 60 years.

\section{PATIENT CLINICAL CHARACTERISTICS}

The subjects were nine women, aged 19 to 65 years, who had been admitted to the hospital between December 1990 and March 1993. Table 1 shows the clinical characteristics of these patients, all of whom underwent neurological evaluation before undergoing surgery. The mean duration of follow up was 3.2 years.

\section{TERMINOLOGY}

Terminology regarding descent of the cerebellar tonsils below the foramen magnum as detected by MRI was according to that established in earlier publications. ${ }^{11-13}$ Briefly, tonsillar herniation of between $1 \mathrm{~mm}$ and 5 $\mathrm{mm}$ is termed tonsillar ectopia. The criterion for the diagnosis of a Chiari malformation is tonsillar displacement to $5 \mathrm{~mm}$ or more below the foramen magnum. ${ }^{11}$
MRI AND DATA ANALYSIS

All patients underwent preoperative MRI which was performed using a $0.5 \mathrm{~T}$ unit (Toshiba TCT 70A-II, Tokyo, Japan). A sagittal multisection sequence (repetition time $(\mathrm{ms}) /$ echo time $(\mathrm{ms})=250 / 14)$ with sections 5 $\mathrm{mm}$ thick was performed.

Nine age and sex matched patients considered not to have disorders that would affect the position of the cerebellar tonsils, were 
Table 1 Clinical characteristics of nine patients with symptomatic tonsillar ectopia

\begin{tabular}{|c|c|c|c|c|c|c|c|c|}
\hline \multirow[b]{2}{*}{$\begin{array}{l}\text { Patient } \\
\text { No }\end{array}$} & \multirow[b]{2}{*}{ Age/sex } & \multicolumn{4}{|c|}{ Preoperative symptoms and signs } & \multirow[b]{2}{*}{$\begin{array}{l}\text { Duration of } \\
\text { symptoms }\end{array}$} & \multirow[b]{2}{*}{$\begin{array}{l}\text { Follow up } \\
\text { period }(y)\end{array}$} & \multirow[b]{2}{*}{$\begin{array}{l}\text { Position of } \\
\text { tonsils }\end{array}$} \\
\hline & & $\begin{array}{l}\text { Occipital } \\
\text { headache }\end{array}$ & Vertigo & $\begin{array}{l}\text { Ataxic unstable } \\
\text { gait }\end{array}$ & Numbness & & & \\
\hline 1 & $65 / \mathrm{F}$ & + & + & - & - & $15 \mathrm{y}$ & 4.5 & $-3 \mathrm{~mm}$ \\
\hline 2 & $56 / \mathrm{F}$ & + & + & - & - & $4 \mathrm{y}$ & 4.5 & $-3 \mathrm{~mm}$ \\
\hline 3 & $51 / \mathrm{F}$ & + & + & + & + & $2 y$ & 2.2 & $-1.5 \mathrm{~mm}$ \\
\hline 4 & $64 / \mathrm{F}$ & + & + & - & - & $1 \mathrm{y}$ & 4 & $-2 \mathrm{~mm}$ \\
\hline 5 & $19 / \mathrm{F}$ & + & + & + & + & 9 months & 4 & $-3 \mathrm{~mm}$ \\
\hline 6 & $56 / \mathrm{F}$ & + & + & - & - & 2 months & 2.1 & $-3 \mathrm{~mm}$ \\
\hline 7 & $61 / \mathrm{F}$ & + & - & - & + & 6 months & 3 & $-3 \mathrm{~mm}$ \\
\hline 8 & $24 / \mathrm{F}$ & + & - & + & - & $2 \mathrm{y}$ & 2.7 & $-4 \mathrm{~mm}$ \\
\hline 9 & $59 / \mathrm{F}$ & + & - & - & - & $6 \mathrm{y}$ & 2.2 & $-4 \mathrm{~mm}$ \\
\hline
\end{tabular}

* The level of the foramen magnum is defined as the basion-opisthion line as detected by MRI. The perpendicular distance from the basion-opisthion line to the tip of cerebellar tonsils was measured.

$-=$ Below the level of the basion-opisthion line.

randomly sampled and subjected to MRI. The extent of tonsillar herniation was measured in the midsagittal plane. The bottom of the foramen magnum was determined by drawing a line from the lowest cortical bone (visualised as a lack of signal) at the inferior tip of the clivus (basion) to the lowest cortical bone at the inferior border of the posterior lip of the foramen magnum (opisthion). ${ }^{14-16}$ Data are expressed as means (SD). Statistical evaluation was performed by unpaired Student's $t$ test to compare the data between two groups. Probability values of $\mathrm{p}<0.05$ were considered to be significant.

\section{NEUROTOLOGICAL EXAMINATIONS}

Preoperative neurotological examination was performed for all patients by one of us (HY) to assess the function of the cerebellovestibular system. Firstly, the possibility of conductive or sensorineural hearing loss was ruled out. Brainstem auditory evoked potentials (BAEPs) were recorded $(90 \mathrm{~dB}, 2.0 \mathrm{kHz}$ click stimulation). The neurotological examination consisted of two parts, one of which was speech audiometry, subdivided into a speech discrimination test and a monaural speech integration test. ${ }^{17}{ }^{18}$ In the other, equilibrium was examined using spontaneous nystagmus evaluation, eye tracking test (ETT; $0.33 \mathrm{~Hz}, 10 \% / \mathrm{s}),{ }^{19}$ optokinetic nystagmus test (OKN test; acceleration $4 \% \mathrm{~s}^{2}$ ) including vertical upward and downward OKN and horizontal optokinetic pursuit (OKP) test, ${ }^{19-21}$ and visual suppression test. ${ }^{22-24}$ ETT patterns were classified according to the system described by Benitez, ${ }^{19}$ as follows: pattern I, smooth sinusoidal tracing; pattern II, a few intermittent non-nystagmic movements every few seconds, superimposed on a sinusoidal curve; pattern III, fast saccadic movements superimposed on an otherwise sinusoidal curve; pattern IV, loss of the sinusoidal curve due to an eye movement imbalance. Patterns I and II are both considered normal. The visual suppression is a visual fixation test in which the maximal slow phase velocity of caloric nystagmus during 10 seconds in the dark $(a)$ is compared with the maximal slow phase velocity during 10 seconds in the light with the eyes open $(b) .{ }^{23}{ }^{24}$ The degree of the visual suppression is quantified using the following formula:

Visual suppression $(\%)=a-b / a \times 100$

Visual suppression of the slow phase velocity of caloric nystagmus is $66(11) \%$ in normal subjects and is considered abnormal when it is less than $40 \%$. $^{23}{ }^{24}$ Postoperative neurotological assessment at two months after surgery was performed for all patients in the same manner by the same author.

\section{Results}

The mean age of the 12 subjects with asymptomatic tonsillar ectopia was 49 and that of the nine patients with symptomatic tonsillar ectopia at the time of diagnosis was 50 . This is higher than the reported mean age of patients with Chiari type I malformation. ${ }^{35-815}$ All of the nine patients were women. The duration of symptoms in these nine patients varied from two months to 15 years, with a mean of 3.5 years. The most common symptom was pain in the occipital area or the posterior cervical region, similar to findings in other studies. ${ }^{56}$ In particular, all of the patients with symptomatic tonsillar ectopia had this symptom. The next most common symptom was vertigo, followed by unstable gait and numbness of the limbs.

The mean tonsillar position in the control group was +2.1 (SD 2.8) $\mathrm{mm}$, whereas it was -2.9 (SD 0.8) $\mathrm{mm}$ in the patients $(\mathrm{p}<0.01)$. Tonsillar displacement below the foramen magnum did not exceed $5 \mathrm{~mm}$ in any of the patients. Although an angulated or peg-like configuration of the tonsils was also characteristic of tonsillar herniation, ${ }^{14}$ none of the patients showed such a deformity of the tonsils. In addition, none of the patients showed syringomyelia.

Table 2 shows the preoperative neurological findings. Four of the nine patients had vibratory sensory disturbance. Superficial sensation was normal in all patients. Patients who complained of numbness did not always have a vibratory sensory disturbance. Three of the nine patients had truncal ataxia, two had limb

Table 2 Preoperative neurological findings

\begin{tabular}{lllll}
\hline $\begin{array}{l}\text { Patient } \\
\text { No }\end{array}$ & $\begin{array}{l}\text { Vibratory sensory } \\
\text { disturbance }\end{array}$ & $\begin{array}{l}\text { Truncal } \\
\text { ataxia }\end{array}$ & $\begin{array}{l}\text { Limb } \\
\text { ataxia }\end{array}$ & $\begin{array}{l}\text { Motor } \\
\text { weakness }\end{array}$ \\
\hline 1 & - & + & + & - \\
2 & + & - & - & - \\
3 & + & + & - & + \\
4 & - & - & - & - \\
5 & + & + & + & + \\
6 & - & - & - & - \\
7 & + & - & - & - \\
8 & - & - & - & + \\
9 & - & - & - & - \\
\hline
\end{tabular}

$+=$ present; $-=$ absent. 
Table 3 Preoperative neurotological findings

\begin{tabular}{|c|c|c|c|c|c|c|c|c|}
\hline \multirow[b]{2}{*}{$\begin{array}{l}\text { Patient } \\
\text { No }\end{array}$} & \multicolumn{3}{|c|}{ Speech audiometry } & \multirow[b]{2}{*}{$\begin{array}{l}\text { Spontaneous } \\
\text { nystagmus }\end{array}$} & \multirow[b]{2}{*}{$B A E P$} & \multirow[b]{2}{*}{$E T T^{\star}$} & \multirow[b]{2}{*}{$O K N$} & \multirow[b]{2}{*}{$\begin{array}{l}\text { Visual } \\
\text { suppression on } \\
\text { calories }\end{array}$} \\
\hline & $\begin{array}{l}\text { Pure tone } \\
\text { audiometry }\end{array}$ & $\begin{array}{l}\text { Speech } \\
\text { discrimination } \\
\text { test }\end{array}$ & $\begin{array}{l}\text { Monoaural speech } \\
\text { integration test }\end{array}$ & & & & & \\
\hline 1 & Abnormal & Normal & Abnormal & + & Abnormal & III & Abnormal & Normal \\
\hline 2 & Normal & Normal & Abnormal & + & Normal & III & Abnormal & Abnormal \\
\hline 3 & Normal & Normal & Abnormal & + & Abnormal & III & Abnormal & Abnormal \\
\hline 4 & Abnormal & Normal & Abnormal & - & Abnormal & III & Abnormal & Abnormal \\
\hline 5 & Normal & Normal & Abnormal & + & Normal & IV & Abnormal & Normal \\
\hline 6 & Normal & Normal & Abnormal & - & Abnormal & II & Abnormal & Abnormal \\
\hline 7 & Normal & Normal & Abnormal & + & Normal & I & Abnormal & Abnormal \\
\hline 8 & Normal & Normal & Abnormal & - & Abnormal & I & Normal & Normal \\
\hline 9 & Normal & Normal & Abnormal & - & Abnormal & I & Abnormal & Abnormal \\
\hline \multicolumn{9}{|c|}{ * According to Benitez's classification. } \\
\hline \multirow[t]{2}{*}{ Table 4} & \multicolumn{8}{|c|}{ Neurotological findings at two months after surgery } \\
\hline & \multicolumn{3}{|c|}{ Speech audiometry } & \multirow[b]{2}{*}{$\begin{array}{l}\text { Spontaneous } \\
\text { nystagmus }\end{array}$} & \multirow[b]{2}{*}{$B A E P$} & \multirow[b]{2}{*}{ ETT } & \multirow[b]{2}{*}{$O K N$} & \multirow[b]{2}{*}{$\begin{array}{l}\text { Visual } \\
\text { suppression on } \\
\text { calories }\end{array}$} \\
\hline $\begin{array}{l}\text { Patient } \\
\text { No }\end{array}$ & $\begin{array}{l}\text { Pure tone } \\
\text { audiometry }\end{array}$ & $\begin{array}{l}\text { Speech } \\
\text { discrimination } \\
\text { test }\end{array}$ & $\begin{array}{l}\text { Monoaural speech } \\
\text { integration test }\end{array}$ & & & & & \\
\hline 1 & Abnormal & NA & Abnormal & - & Abnormal & I & Improved & NA \\
\hline 2 & NA & NA & Improved & - & NA & II & Improved & Improved \\
\hline 3 & NA & NA & Improved & - & Improved & $\mathrm{I}$ & Improved & Normalised \\
\hline 4 & Normalised & NA & Improved & NA & Improved & II & Improved & Normalised \\
\hline 5 & NA & NA & Improved & + & NA & II & Improved & NA \\
\hline 6 & Abnormal & NA & Improved & NA & Improved & I & Improved & Normalised \\
\hline 7 & NA & NA & Improved & + & $\mathrm{NA}$ & I & Improved & Improved \\
\hline 8 & NA & NA & Abnormal & NA & Improved & I & $\mathrm{NA}$ & $\mathrm{NA}$ \\
\hline 9 & NA & NA & Improved & NA & Improved & I & Improved & Normalised \\
\hline
\end{tabular}

NA $=$ not applicable. For the other abbreviations see table 3.

ataxia, and three had motor weakness. Three of the patients were neurologically normal. Because the symptoms and neurological findings were not specific to tonsillar ectopia, we performed neurotological examinations to elucidate the posterior fossa pathology. Table 3 shows the results of the preoperative neurotological examinations. Seven of the nine patients showed normal hearing levels for pure tones but all nine showed hearing loss in the monaural speech integration tests. These findings indicated the presence of CNS lesions. Spontaneous nystagmus, which is due to dysfunction of the cerebellovestibular system, was evident in five of the nine patients $(56 \%)$ and ETT disclosed an abnormal pattern in five (56\%): pattern III in four and pattern IV in one. All but one of the patients showed an abnormal OKN response. The visual suppression test results were less than $40 \%$ for six of the patients $(67 \%)$.

All nine patients underwent posterior fossa decompression surgery, including a suboccipital craniectomy with duraplasty. We did not perform a C1 laminectomy because the descent of the cerebellar tonsils was slight. The arachnoid membrane was not penetrated. Table 4 shows the results of the neurotological assessment performed two months after surgery. One patient (6) had transient sensorineural hearing loss. Afterwards, the patient showed normal hearing levels for pure tones. Seven of the nine patients showed improved hearing levels in the monaural speech integration tests. Spontaneous nystagmus disappeared in three of the patients. ETT and OKN disclosed an improved pattern in all patients who had shown an abnormal pattern preopera- tively. The visual suppression test results were improved in two of the six patients in which it was applicable and returned to a normal pattern in four of the six patients.

\section{REPRESENTATIVE CASE REPORT}

\section{Patient 4}

A 64 year old Japanese woman was admitted to hospital in June 1991 with a one year history of headache, neck pain in the posterior cervical region, and vertigo. Her medical history was unremarkable. The neurological findings were also unremarkable. Brain MRI disclosed $2 \mathrm{~mm}$ descent of the cerebellar tonsils below the foramen magnum (fig 1). Neurotological examination showed normal hearing levels for pure tones, normal speech discrimination ability, an abnormal monaural speech integration test, prolonged I-III interpeak latency in the left ear responses of BAEPs, an abnormal ETT result (pattern III), suppressed vertical downward OKN and horizontal OKP, and failure of visual suppression $(<40 \%)$ in a right cold caloric response test (fig 2). Based on these findings, the patient underwent posterior fossa decompression surgery. The postoperative course was uneventful. She was discharged one month after surgery without complaint. The neurotological examination performed two months after the surgery disclosed an improved monaural speech integration test result, shortened I-III interpeak latency in the left ear responses of BAEPs, improved vertical downward OKN, normalised horizontal OKP, and visual suppression in right cold caloric response tests despite a persistent dysmetric eye tracking pattern (fig 3 ). 


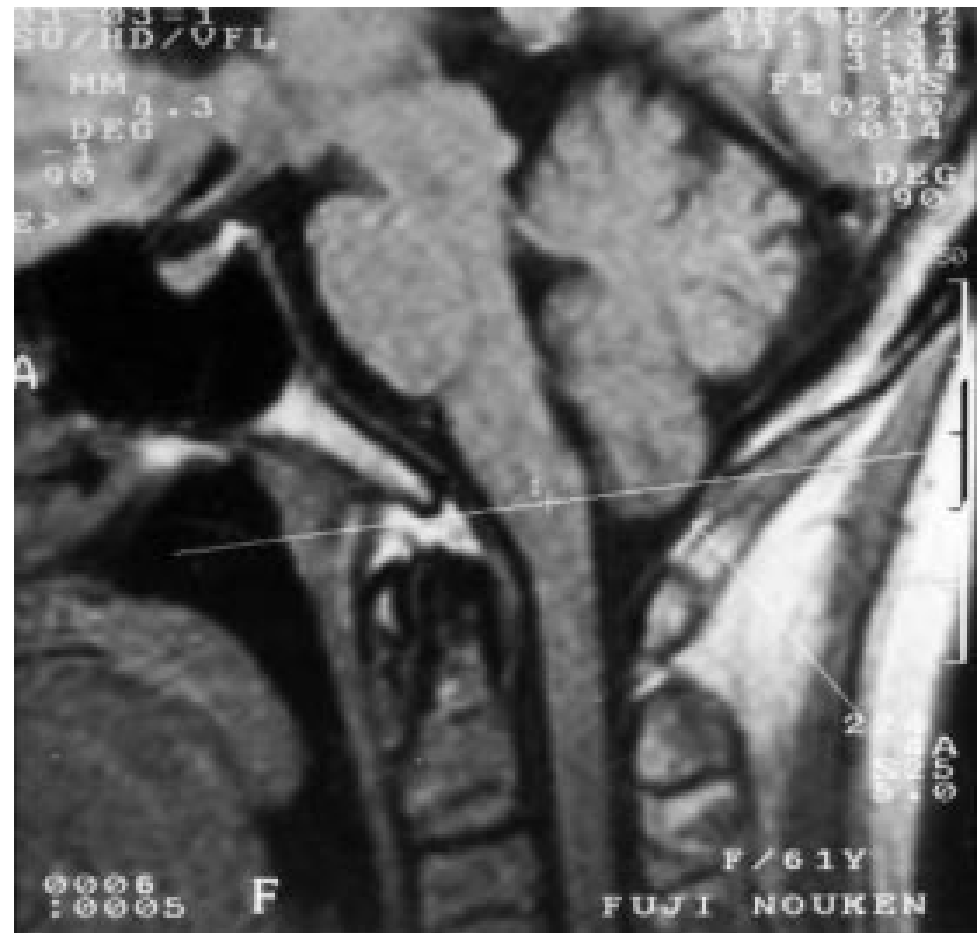

Figure 1 T1 weighted midsagittal MRI of patient 4. White line indicates the basion-opisthion line. The tonsillar position is $2 \mathrm{~mm}$ below the foramen magnum. The cerebellar tonsil is oval shaped rather than having a peg-like configuration.
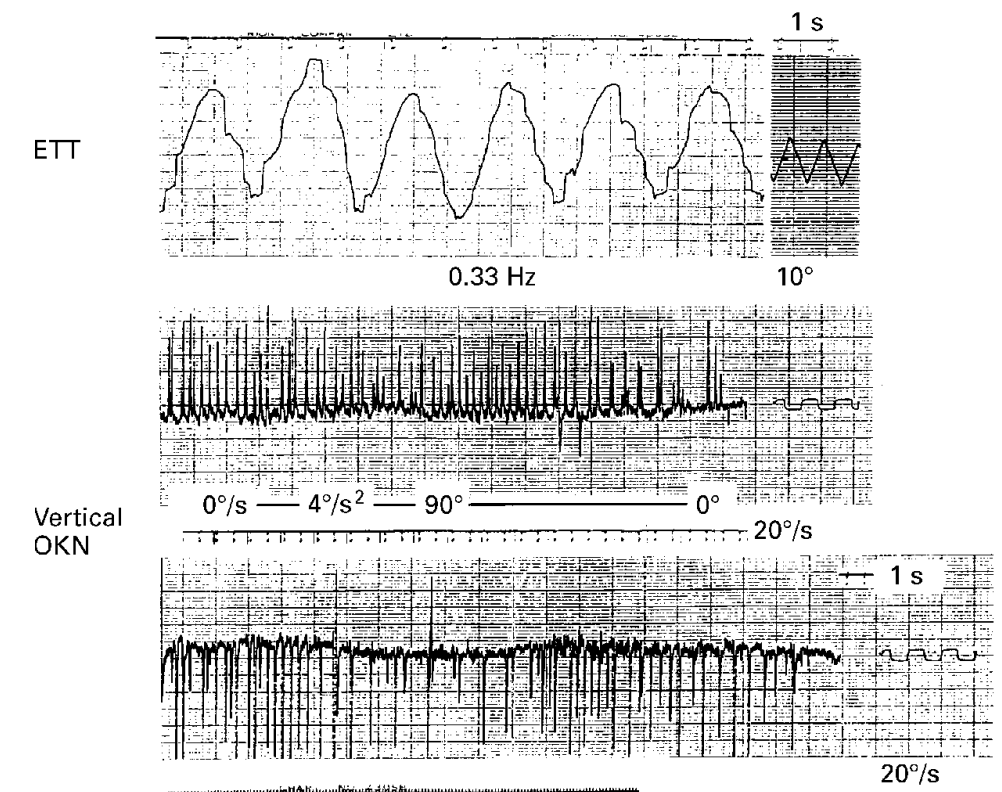

OKP

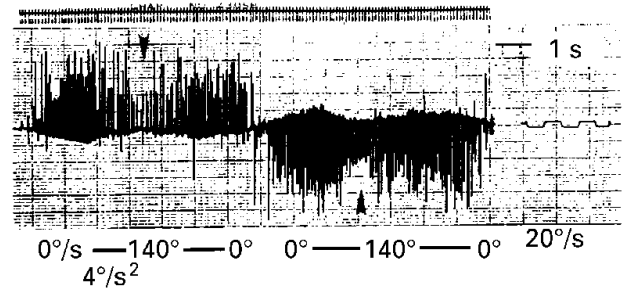

Figure 2 The preoperative neurotological findings for patient 4. An eye tracking test (ETT) shows an abnormal response (pattern III on Benitez's classification). An optokinetic nystagmus (OKN) test shows a suppressed vertical downward response. Horizontal optokinetic pursuit (OKP) shows a suppressed response (arrowheads).

\section{Discussion}

The results of this study show that some patients who present with tonsillar ectopia as detected by MRI have a variety of symptoms and signs, although several authors have measured the degree of tonsillar herniation and determined that a low degree of herniation is often of no clinical importance. ${ }^{112} 14$ Brain MRI provides an excellent non-invasive means of studying the cerebellar tonsils and their relation to the foramen magnum. ${ }^{379141525}$ Aboulez et al reported that on T1 weighted images in the sagittal plane, the average distance from the tonsillar tips to the foramen magnum ranged from $2.9 \mathrm{~mm}$ above to $3.4 \mathrm{~mm}$ below. $^{25}$ They indicated that extension of the tonsils to up to $3 \mathrm{~mm}$ below the foramen magnum can be considered normal and that extension is clearly pathological only when it exceeds $5 \mathrm{~mm}$. Barkovich et al measured the position of the cerebellar tonsils in 200 randomly selected patients and in 25 patients with a firm diagnosis of Chiari malformation. ${ }^{14}$ They reported that MRI demonstration of less than $2 \mathrm{~mm}$ of tonsillar ectopia was probably of no clinical relevance in the absence of syringomyelia. The tonsillar position in the Japanese tends to be higher than that in Americans. ${ }^{15}{ }^{16}$ This tendency was also found in the control group in the present study. The higher position of the tonsils in the Japanese may be accounted for by genetic differences. ${ }^{16}$ In addition, the finding of $100 \%$ concordance of tonsillar ectopia in monozygotic triplets is highly suggestive of a common hereditary origin. ${ }^{13}$ The tonsillar position moves cephalad to the foramen magnum with increasing age. ${ }^{16}$ Based on the above findings, we conclude that tonsillar ectopia could cause symptoms in Japanese people.

It is uncertain at present how tonsillar ectopia could cause cerebellovestibular dysfunction. However, some neurotologists have postulated that in cases of Chiari type I malformation, cerebellovestibular dysfunction is caused by compression of the vestibular and cochlear nuclei by the herniated tonsils, stretching of the cochleovestibular nerve over the porus acousticus, and ischaemia caused by distortion of the posterior inferior cerebellar artery or one of its branches. ${ }^{26}{ }^{27}$ We performed neurotological examinations to elucidate the aetiological relation between tonsillar ectopia and various symptoms. The reasons why we adopted neurotological examination as a diagnostic method are that several authors strongly emphasised the importance of careful neurotological examination in the diagnosis of Chiari malformation, ${ }^{26-32}$ and that although not usually considered typical presenting complaints, neurotological findings were often present and might even have preceded the development of the more severe and obvious neurological complaints. ${ }^{30}$ Usually patients with CNS lesions have hearing loss in the speech range, although they show no impairment of hearing of pure tones. ${ }^{32}$ Under ordinary conditions, the redundancy of the elements of information contained in an ordinary speech wave insures the intelligibility of a message, even though only one of the factors of the equation varies. ${ }^{18}$ 
ETT

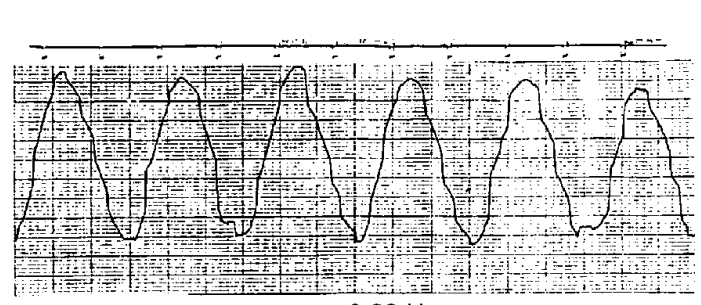

$0.33 \mathrm{~Hz}$

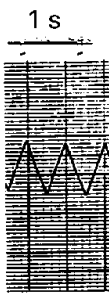

$10^{\circ}$

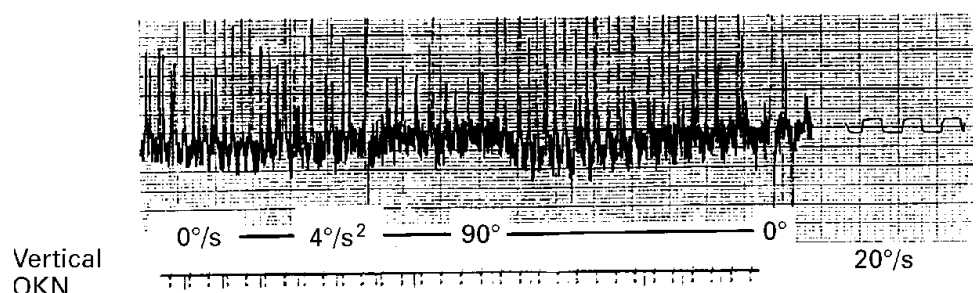

OKN
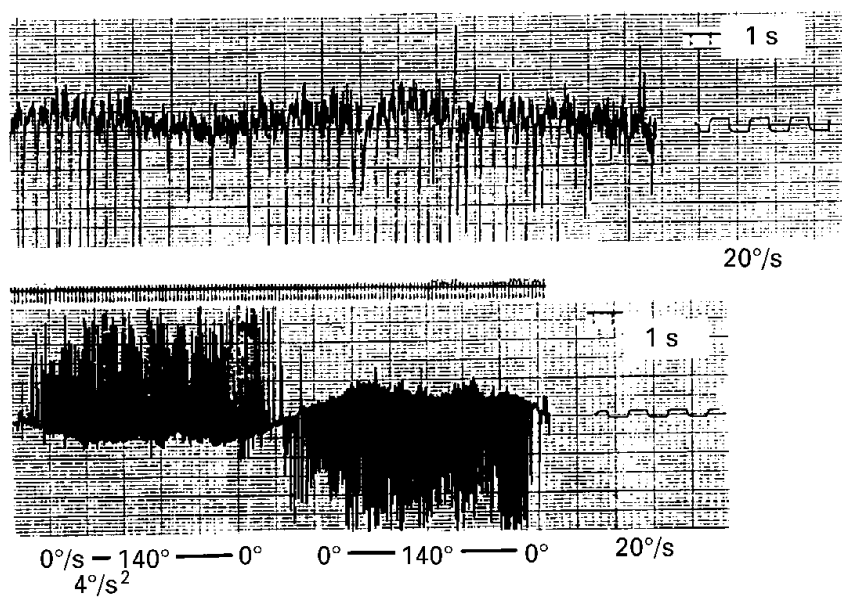

Figure 3 Neurotological findings two months after surgery in patient 4. An eye tracking test (ETT) shows a persistent dysmetric pattern. An optokinetic nystagmus (OKN) test shows an improved vertical downward response and normalised horizontal optokinetic pursuit. arc. ${ }^{19-21}$ Both reflex arcs share the final oculomotor pathways from the oculomotor nuclei to the eye muscles with the fixation reflex arc, which is usually evaluated for the fixation effect on spontaneous or induced vestibular nystagmus. Horizontal visual field testing is routine in cases suggestive of a CNS lesion, although vertical visual field testing is at times also very important. ${ }^{21} \mathrm{~A}$ bidirectionally reduced OKN response, either symmetric or asymmetric, indicates the presence of CNS disease, usually in the brainstem or the cerebellum. ${ }^{21}$ In the present study, all but one of the patients showed a bidirectionally reduced OKN response.

Visual fixation either suppresses or abolishes caloric nystagmus in normal subjects and patients with peripheral vestibular disorders. ${ }^{22}$ However, in patients with metabolic encephalopathy, or brainstem or cerebellar disease, visual fixation fails to suppress or may even enhance caloric nystagmus. ${ }^{22}$ This sign has been termed "failure of fixation suppression". Alpert stated that failure of fixation suppression was highly correlated with posterior fossa pathology, provided that there had been no recent drug intake. ${ }^{22}$ Six of the nine patients in the present study scored below $40 \%$ in the visual suppression test. There has been much speculation regarding the anatomical site of visual-vestibular interaction.

Yules et al stressed the importance of the pontine and midbrain reticular formation in mediating the vestibulo-ocular reflex arc. $^{34}$ However, Lorente reported that in the vestibular system, there is no "localisation" of reflexes in anatomical nuclei, and that the whole system is a functional unit. ${ }^{35}$ Finally, we stress that symptomatic tonsillar ectopia is associated with no single pattern of neurotological findings; rather, a combination of findings suggesting the presence of a CNS lesion contributes to the diagnosis.

One patient (6) had transient sensorineural hearing loss postoperatively. The labyrinth of the pyramidal bone consists of the membranous labyrinth enclosed within the channels of the bony labyrinth. A space containing perilymphatic fluid lies between the periosteum of the bony labyrinth and the membranous labyrinth, whereas the spaces within the membranous labyrinth contain endolymphatic fluid. The CSF enters the perilymphatic space through a narrow channel known as the cochlear aqueduct, located at the base of the scala tympani. ${ }^{33}$ We do not know precisely how the transient sensorineural hearing loss occurred in this patient, but the most plausible explanation is that the pattern of CSF flow or the CSF pressure in the posterior fossa changed on posterior fossa decompression and then the pressure in the perilymphatic space decreased through the cochlear aqueduct causing the sensorineural hearing disturbance. This condition might have persisted until homeostasis of the CSF pressure in the perilymphatic space was reached.

The differential diagnosis of symptomatic tonsillar ectopia must include cervicogenic headache. Stimulation of parts of the vertebral 
column, the cervical muscles and their attachments to bone, the cervical nerve roots, and the vertebral arteries under such conditions as arthritis, trauma, infection, tumour, dissection, or atherothrombotic occlusion of the vertebral arteries clearly gives rise to pain. ${ }^{36}$ Brain MRI may be useful for distinguishing symptomatic tonsillar ectopia from these conditions. The differential diagnosis must also include vertebrobasilar insufficiency. In the present cases, we did not perform angiography to rule out vertebrobasilar insufficiency because none of the patients had a medical history that included hypertension or diabetes mellitus which might cause arteriosclerosis. Ausman et al recommended that for patients with symptoms thought to be related to diseases of the vertebrobasilar territory that are unexplained by other systemic causes, angiography should be performed to help establish the diagnosis. ${ }^{37}$ The following symptoms as well as transient ischaemic attacks which occasionally occur in patients with vertebrobasilar insufficiency have never been found in patients with symptomatic tonsillar ectopia: diplopia, dysphagia, binocular or monocular visual changes, or syncope. ${ }^{37}$ Moreover, MRI disclosed no brainstem or cerebellar infarct in the present cases. We conclude that angiography of the vertebrobasilar system is not always necessary to rule out vertebrobasilar insufficiency.

In conclusion, tonsillar ectopia may cause symptomatogenesis in small populations with this anatomical finding. Neurotological examination was necessary to verify the cerebello-vestibular dysfunction because healthy persons occasionally show tonsillar ectopia as detected by MRI. Surgery for posterior fossa decompression was a safe and effective means of relieving the symptoms.

We hope that further research on symptomatic tonsillar ectopia will contribute not only to our understanding of the symptomatogenic mechanism but to elucidation of its aetiological significance.

1 Chiari $\mathrm{H}$. Über Veränderungen des Grosshirns infolge von Hydrocephalie des Grosshirns. Dtsch Med Wochenschr 1891;17:1172-5.

2 Chiari H. Über Veränderungen des Kleinhirns, des Pons und der Medulla oblongata infolge von kongenitaler
Hydrocephalie des Grosshirns. Denkschriften der KaiserHydrocephalie des Grosshirns. Denkschriften der Kaiser-
lichen Akademie der Wissenschaften (Wien) 1895;63:71-116.

3 Dyste GN, Menezes AH, VanGilder JC. Symptomatic Chiari malformations: an analysis of presentation, management, and long-term outcome. $\mathcal{F}$ Neurosurg 1989;71:15968.

4 Friede RL, Roessmann U. Chronic tonsillar herniation: an attempt at classifying chronic herniations at the foramen magnum. Acta Neuropathol 1976;34:219-35.

5 Levy WJ, Mason L, Hahn JF. Chiari malformation presenting in adults: a surgical experience in 127 cases. Neurosurgery 1983;12:377-90.
6 Paul KS, Lye RH, Strang FA, et al. Arnold-Chiari Paul KS, Lye RH, Strang FA, et al. Arnold-Chiar
malformation: review of 71 cases. $\mathcal{f}$ Neurosurg 1983;58 malfor

7 Pillay PK, Awad IA, Little JR, et al. Symptomatic Chiari malformation in adults: a new classification based on magnetic resonance imaging with clinical and prognostic significance. Neurosurgery 1991;28:639-45.

8 Saez RJ, Onofrio BM, Yanagihara T. Experience with Arnold-Chiari malformation, 1960-70. I Neurosurg 1976; 45:416-22.

9 Sathi S, Stieg PE. Aquired Chiari I malformation after multiple lumbar punctures: case report. Neurosurgery 1993;32: 306-9.

10 Welch K, Shillito J, Strand R, et al. Chiari I "malformation" - an acquired disorder ? $\mathcal{F}$ Neurosurg 1981;55:604-9.

11 Barkovich AJ. Congenital malformations of the brain. In: Barkovich AJ, ed. Pediatric neuroimaging, 1st ed. New York: Raven, 1990:108.

12 Castillo M. Imaging of Chiari malformations. Appl Radiol 1992;5:31-5.

13 Cavender RK, Schmidt III JH. Tonsillar ectopia and Chiari malformations: monozygotic triplets. Case report. 7 Neurosurg 1995;82:497-500.

14 Barkovich AJ, Wippold FJ, Sherman JL, et al. Significance of cerebellar tonsillar position on MR. AfNR Am $\mathcal{F}$ Neuroradiol 1986;7:795-9.

15 Ishikawa M, Kikuchi $H$, Fujisawa I, et al. Tonsillar herniation on magnetic resonance imaging. Neurosurgery 1988;22:77-81.

16 Mikulis DJ, Diaz O, Egglin TK, et al. Varience of the position of the cerebellar tonsils with age: preliminary report. Radiology 1992;183:725-8.

17 Bocca BE, Calearo C, Cassinari V. A new method for testing hearing in temporal lobe tumors: preliminary report. Acta Otolaryngol 1954;44:219-21.

18 Calearo C, Lazzaroni A. Speech intelligibility in relation to the speed of the message. Laryngoscope 1957;67:410-9.

19 Benitez JT. Eye-tracking and optokinetic tests: diagnostic significance in peripheral and central vestibular disorders. Laryngoscope 1970;80:834-48.

20 Coats AC. Central electronystagmographic abnormalities. Arch Otolaryngol Chir Cervicofac 1970;92:43-53.

21 Hart CW. The optokinetic test and the ENG test battery. Ann Otol Rhino Laryngol Suppl 1981;86:2-6.

22 Alpert JN. Failure of fixation suppression: a pathologic effect of vision on caloric nystagmus. Neurology 1974;24: $891-6$

23 Takemori S. Visual suppression test. Adv Otorhinolaryngol 1983;29:102-10.

24 Takemori S. Visual suppression test. fi-Bi To Rinshou (Tokyo) 1982;75:1973-8. (In Japanese.)

25 Aboulezz AO, Sartor K, Geyer CA, et al. Position of cerebellar tonsils in the normal population and in patients with Chiari malformation: a quantitative approach with MR imaging. f Comput Assist Tomogr 1985;9:1033-6.

26 Rydell RE, Pulec JL. Arnold-Chiari malformation: neurootologic symptoms. Archives of Otolaryngology 1971;94:812 .

27 Bertrand RA, Martinez SN, Robert F. Vestibular manifestations of cerebellar ectopia. Adv Otorhinolaryngol 1973;19. 355-66.

28 Chait GE, Barber HO. Arnold-Chiari malformation-some otoneurological features. F Otolaryngol 1979;8:65-70.

29 Longridge NS, Mallinson AI. Arnold-Chiari malformation and the otolaryngologist: place of magnetic resonance maging and electronystagmography. Laryngoscope 1985; 95:335-9.

30 Sclafani AP, DeDio RM, Hendrix RA. The Chiari-I malformation. Ear Nose Throat f 1991;70:208-12.

31 Hendrix RA, Bacon CK, Sclafani AP. Chiari-I malformation associated with asymmetric sensorineural hearing loss. $\mathcal{f}$ Otolaryngol 1992;21:102-7.

32 Albers FWJ, Ingels KJAO. Otoneurological manifestations in Chiari-I malformation. F Laryngol Otol 1993;107:441-3.

33 Baloh RW. Neurotology. In: Wilkins RH, Rengachary SS, Baloh RW. Neurotology. In: Wilkins RH, Rengachary SS,
eds. Neurosurgery. Vol 1. New York: McGraw-Hill, 1985: eds. Neur $111-6$.

34 Yules RB, Krebs CQ, Gault FP. Reticular formation control of vestibular system. Exp Neurol 1966;16:349-58.

35 Lorente de No R. Vestibulo-ocular reflex arc. Arch Neurol Psychiatry 1933;30:245-91.

36 Edmeads J. The cervical spine and headache. Neurology 1988;38:1874-8.

37 Ausman JI, Shrontz CE, Pearce JE, et al. Vertebrobasilar insufficiency: a review. Arch Neurol 1985;42:803-8. 